TI 2014-034/VII

Tinbergen Institute Discussion Paper

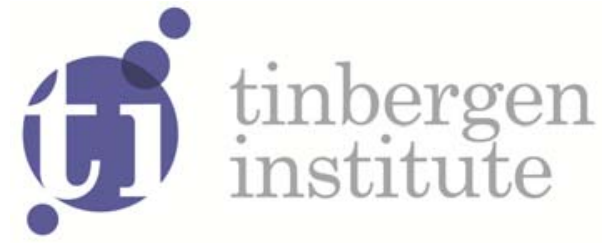

\title{
Task-specific Human Capital and Organizational Inertia
}

Josse Delfgaauw

Otto H. Swank 
Tinbergen Institute is the graduate school and research institute in economics of Erasmus University Rotterdam, the University of Amsterdam and VU University Amsterdam.

More TI discussion papers can be downloaded at http://www.tinbergen.nl

Tinbergen Institute has two locations:

Tinbergen Institute Amsterdam

Gustav Mahlerplein 117

1082 MS Amsterdam

The Netherlands

Tel.: +31(0)205251600

Tinbergen Institute Rotterdam

Burg. Oudlaan 50

3062 PA Rotterdam

The Netherlands

Tel.: +31(0)10 4088900

Fax: $+31(0) 104089031$

Duisenberg school of finance is a collaboration of the Dutch financial sector and universities, with the ambition to support innovative research and offer top quality academic education in core areas of finance.

DSF research papers can be downloaded at: http://www.dsf.nl/

Duisenberg school of finance

Gustav Mahlerplein 117

1082 MS Amsterdam

The Netherlands

Tel.: +31(0)20 5258579 


\title{
Task-specific human capital and organizational inertia
}

\author{
Josse Delfgaauw* and Otto Swank ${ }^{\dagger}$
}

March 2014

\begin{abstract}
Employees' incentive to invest in their task proficiency depends on the likelihood that they will execute the same tasks in the future. Changes in tasks can be warranted as a result of technological progress and changes in firm strategy as well as from fine-tuning job design and from monitoring individuals' performance. However, the possibility of a change in tasks reduces employees' incentive to invest in task-specific skills. We develop a simple two-period principal-agent model showing that some degree of inertia benefits the principal. We then analyze how organizations can optimally combine several policies to approach the optimal degree of inertia. In particular, we consider the optimal mixture of (abstaining from) exploration, managerial vision, organizational task-specific investments, and incentive pay. Our analysis yields testable predictions concerning the relations between these organizational policies.
\end{abstract}

JEL-Codes: D23, D83, D92

Keywords: Task-specific human capital, organizational inertia, time-inconsistency, exploration, exploitation

\footnotetext{
*Erasmus University Rotterdam and Tinbergen Institute. E-mail: delfgaauw@ese.eur.nl.

${ }^{\dagger}$ Erasmus University Rotterdam and Tinbergen Institute. E-mail: swank@ese.eur.nl.
} 


\section{Introduction}

One of the best-known virtues of competition is that it provides incentives to firms and individuals to search for new opportunities to improve upon current practice. For Schumpeter, this process of creative destruction is an essential feature of capitalism. He regards it as a prerequisite for dynamic efficiency. In the present paper we argue that although the continuous search for new opportunities is widely regarded as a social blessing, within firms it provides a challenge when workers can invest in task-specific productivity. In an environment where workers anticipate that current practices or activities are possibly replaced by new tasks, workers may be reluctant to invest in their aptitude to perform their current activities. This reduces their productivity in the current task, which in turn makes it even more likely that management decides to switch to a new task assignment. When workers' investment in task-specific human capital is sufficiently important, firms benefit from reducing the probability of changes in future task assignments. In this paper, we analyze when and how organizations can induce some degree of inertia.

In the management literature, organizational inertia is a much-discussed phenomenon (March 1981, 1991, Hannan and Freeman 1984, Rumelt 1995, Schreyögg and Sydow 2011 and the references therein). Organizations tend to develop procedures and routines that, once established, are hard to change fundamentally (Nelson and Winter 1982). Rigidity and inflexibility are typically seen as inherently bad for organizations, as it limits organizations' response to changes in the environment and technology (March 1991, LeonardBarton 1992, Ford et al. 2008). In contrast, Hannan and Freeman (1984) argue that reliable and accountable organizations have an edge in a competitive environment. This favors organizations that develop a set of routines generating stable outcomes, which become a source of inertia. ${ }^{1}$ One source

\footnotetext{
${ }^{1}$ This also implies that inertia will be larger in older organizations, also observed by Downs (1967) in public bureaucracies. Ruef (1997) studies the response of Californian hospitals to the introduction of new technologies and changes in regulation between 1980 and 1990, and finds that relatively few hospitals offer new services in response to these environmental changes. In particular older, larger, and more specialized hospitals are less likely to change. Kelly and Amburgey (1991) find that airlines hardly changed their product mix in response to major deregulations in the late 1970's, with older airlines being most inert. Instead, in this period, many new airlines were founded. Studying Finnish newspapers, Amburgey et al. (1993) finds that older organizations are less likely to change their content and their frequency of publication.
} 
of inertia is known as the competency trap (Levitt and March 1988), where organizations keep using inferior technologies and procedures because of inexperience with superior alternatives. ${ }^{2}$ When employees have vested abilities and knowledge, they may resist changes that reduce the value of their specific skills (March 1991, Rumelt 1995). While acknowledging this, we argue that organizations can benefit from cultivating some degree of inertia, exactly because it gives employees incentives to invest in skills specific to their current tasks. ${ }^{3}$

A key feature of our model is that employees' task proficiency increases in experience with performing the task. Evidence on this abounds. Lance et al. (1989) show that for jet engine mechanics, experience with performing a particular task is highly correlated with performance in that task. Schmidt et al. (1986) find that for several military occupations, supervisor ratings and work sample performance increase in experience in the job, mostly through an increase in knowledge on how tasks should be performed. In a metaanalysis on the relation between performance and experience, Quifiones et al. (1995) find that both job experience and experience with performing a task are positively correlated with performance, but the correlation between performance and task experience is stronger than the correlation between performance and job experience (see also Jovanovic and Nyarko (1995) for evidence of leaning-by-doing in various settings and Waldman et al. (2003) for references on learning-by-doing in health care). ${ }^{4}$ It follows that in making investments in task-specific human capital, people should take (potential)

\footnotetext{
${ }^{2}$ There is a large literature documenting that the diffusion of new technology is slow (Griliches, 1957, Stoneman 1983, Chari and Hopenhayn 1991, Jaffe and Stavins 1994, Jovanovic and MacDonald 1994), or that inferior technology remains in use despite superior alternatives (Shama 1983, David 1985, Katz and Shapiro 1986).

${ }^{3}$ In the literature on organizational learning and routines (March 1981, Nelson and Winter 1982) it is emphasized that routines are often changed incrementally. Such incremental changes will typically not affect employees' tasks and, hence, are not considered in this paper. The same holds for small changes in product design or marketing strategy. Using Hannan and Freeman (1984)'s hierarchy of organizations' inflexible core, changes in organizational goals, forms of authority, and core technology would affect employees' tasks more strongly than changes in marketing strategy.

${ }^{4}$ Task-specific human capital also matters for labor market outcomes. Using detailed data on tasks performed in different occupations, Gathmann and Schönberg (2010) show that experience with performing specific tasks strongly influences job mobility and wage growth. People are more likely to switch to jobs that are close to their current job in terms of relative importance of task-specific skills, and wage growth for job movers increases in their experience with performing the most important tasks in their new job (see also Poletaev and Robinson 2008).
} 
future changes in tasks into account (Lazear 2009). We argue that this provides a rationalization for some degree of organizational inertia. If employees anticipate that their organization responds slowly to future changes in the environment or technology, investments in their current task-specific skills are more likely to also be valuable in the future. The cost of inertia is that the organization does not adapt as well as possible to its environment.

Employees may be reluctant to invest time and effort enhancing their productivity in their current task due to uncertainty about future task assignment. Firm-level changes, such as changes in strategy or production technology, reduce the value of employees' earlier strategy- or technologyspecific investments. Changes at the job level can have a similar impact. Consider a university lecturer who is asked to teach a new undergraduate course outside his main research area. He knows that if he will be teaching this course for several years, it is worthwhile to make a big initial investment. However, if within a few years the department hires someone whose research expertise perfectly suits the course, it is likely that the course is shifted to the new hiree, which would imply that the lecturer hardly benefits from his initial investment. Similarly, an account manager needs to build up a relation with a new client, but knows that management may decide to reallocate the client to one of his colleagues. A good secretary learns how her superior wants to be supported, but this knowledge has no value when her superior is replaced. Employees' productivity in working with firm-specific IT depends on their investment in grasping all possibilities of the system, which is useless if the firm switches to a new system. These examples suggest that if employees' investment is sufficiently important, organizations could benefit from introducing policies that reduce the probability of a change in tasks.

In this paper, we first study the trade-off between employees' incentives to invest in task-specific productivity and optimal task replacement. Next, we analyze (the optimal combination of) several policies that allow organizations to affect this trade-off. We develop a simple two-period principal-agent model where the agent's first-period effort also has a payoff in the second period, unless the first-period task is replaced in period 2. In period 1 , the principal can engage in exploration of an alternative task. This yields information on the productivity of an alternative task relative to the current task. Despite the first-period investment in productivity in the initial task, 
the alternative task can be more productive. We show that the principal suffers from a time-inconsistency problem: the principal would benefit from an ex ante commitment to maintain the current task for a range of tasks' relative productivity where replacement is optimal ex post. Whereas this commitment is costly in terms of sub-optimal second-period task assignment, it benefits the principal through an increase in the agent's first-period effort spurred by the increased probability that this effort also matters for second-period performance. Such commitment, however, requires verifiable information on tasks' relative productivity, which is typically not present.

The objective of this paper is to analyze how organizations can optimally combine several policies that alleviate the commitment problem described above. In particular, we consider the combination of (i) abstaining from exploration, (ii) managerial vision, (iii) organizational task-specific investments, and (iv) incentive pay. We show that strategically abstaining from exploration can be beneficial, in particular in relatively stable environments as well as when the firm can invest in task-specific productivity alongside the employee's investments. In the absence of exploration, employees are certain that current practices will not be replaced, which increases the payoff of investing in task-specific skills. The downside is that profitable alternatives are missed.

We further show that managerial vision or an organizational mission may mitigate the commitment problem, provided that the agent shares the mission. As in Rotemberg and Saloner (2000) and Van den Steen (2005), we model managerial vision as a bias of the principal (or manager) towards current activities. This bias is possibly shared by the agent. A direct implication of this bias is that the principal is less inclined to replace the current activity, making it more likely that the agent's first-period effort has a payoff in the second period. However, from the perspective of a neutral agent, the principal's bias also implies that the task is not replaced when there is moderately better alternative. This reduces the agent's incentive to put in effort. These two effects cancel out, unless the agent (partially) internalizes the mission. Hence, in contrast to the results in Rotemberg and Saloner (2000) and Van den Steen (2005), in our setting visionary leadership alone is not enough to make workers more engaged. Workers should be truly inspired..$^{5}$

\footnotetext{
${ }^{5}$ This result is consistent with Wilson (1989), who discusses many examples of public
} 
Incentive pay helps to increase first-period effort, and thereby alleviates but not eliminates the commitment problem, provided that the employee earns a rent. We show that incentive pay and organizational missions are substitutes. If the organizational mission encourages employees to put in high effort, this yields high cost of incentive pay. Hence, if the organizational mission or managerial vision is more inspiring, monetary incentives are optimally weaker.

Furthermore, we show that both incentive pay and the strength of the organizational mission are optimally higher when the firm can make taskspecific investments. Organizational task-specific investments, such as specific equipment, software, or training have a lasting effect on the productivity of the initial task, which reduces the probability that the task is replaced. This, in turn, increases the employee's incentive to invest in task-specific skills, which further increases the probability that the firm's investment has a second-period payoff. Hence, the firm's investment and the employee's learning-by doing are complements through their effects on the probability of task replacement, even in the absence of direct interaction effects in the production function. Consequently, organizational policies that increase employee's effort, in particular missions and incentive pay, are more valuable when the firm makes specific investments.

Our final results concern comparisons across organizations. The cost of organizational policies that increases employee's investment in task-specific human capital by reducing the probability of task replacement depends on the stability of the environment. In volatile environments, reducing flexibility is more costly than in stable environments. Hence, we predict that firms that engage in exploration in relatively stable environments use incentive pay, missions, and task-specific investment to a larger extent than firms in more volatile environments. This implies that even though incentive pay and managerial vision are substitutes, without properly controlling for the volatility of the environment (as well as for organizational investment) we may observe a positive association across organizations. Lastly, we predict that firms that do not engage in exploration are more specialized and make use of missions and incentive pay to a smaller extent than firms that do engage in exploration.

We believe that our analysis contributes to the literature on organizamanagers who (try to) motivate agents by installing a sense of a mission in the agents. 
tional ambidexterity, defined as firms' policy to engage in both exploration and exploitation (Benner and Tushman 2003, Greve 2007, Lavie et al. 2009). For instance, our results can explain why organizations combine a focus on exploration in particular area's with a focus on exploitation in other area's, as documented by Voss and Voss (2013). Benner and Tushman (2003) and Gupta et al. (2006) state that some firms may be better off specializing in either exploration or exploitation. Our analysis yields predictions regarding the differences in incentive pay, missions, and specific investments between ambidextrous firms and firms that specialize in exploitation. Moreover, we predict how these organizational policies are optimally determined in relation to the (relative) importance of exploration. Hence, our analysis provides predictions concerning "the mediators and moderators that may affect the ambidexterity-performance relationship" as called for by Raisch et al. (2009, p. 693).

From an evolutionary perspective, our results allow for an alternative interpretation. Even when organizations do not deliberately create inertia, our analysis predicts that in organizations where inertia arises, employees' investment in task-specific human capital is higher. In environments where such investments are crucial, we predict that an organization is more likely to survive when (the combination of) managerial vision, firm's task-specific investments, and incentive pay create barriers to change.

Whether and how organizations can affect the degree of inertia in particular tasks and processes is a central concern in the recent literature on organizational path dependence and organizational rigidities (Sydow et al. 2009, Schreyögg and Sydow 2011). While this literature emphasizes the importance of contingencies and self-reinforcing mechanisms, Garud et al. (2010) argue that actors may have means to affect the course of the path. Vergne and Durand (2011) argue that managers may be able to select into and out of paths at the early stage of path development. Our analysis aims to highlight the policies managers can use to affect path development that arises from learning-by-doing.

\section{Related Literature}

Gibbons and Waldman (2006) introduce task-specific human capital, assuming that workers build up task-specific skills that are lost when they get 
promoted to a higher level in the organizational hierarchy. In their framework, this can explain cohort effects in wages, provided that a relatively large fraction of workers who enter the organization in bad times start at a low job level. While in Gibbons and Waldman (2006) task-specific capital is accumulated automatically, we study workers' incentive to invest in such task-specific skills, knowing that the skills may become obsolete after a change in task assignment. Lazear (2009) argues that firms differ in the relative importance of different generic skills. He shows that it is less attractive for workers to adjust their investment in skills to their current firm's skill-weights when the probability of an exogenous layoff is large and they are unlikely to find another firm where their skills have similar relative value. Hence, the current firm has to pay for part of the investment in generic skills. In a straightforward reinterpretation of our model, the different tasks utilize the agent's skills to a different degree. Technological advances or competitive forces could call for a change in the agent's job design, reducing the value of skill-weight-specific investments. ${ }^{6}$

Boyer and Robert (2006) explain inertia from a dynamic incentive framework, where the cost of providing incentives for developing successful a project increases in the probability that the project will not be implemented due to the arrival of a more profitable opportunity ex post. Our paper shares the trade-off between ex ante incentives and ex post project choice that gives rise to some optimal degree of inertia. However, where Boyer and Robert (2006) assume that firms can contractually commit to ignore profitable projects, we analyze several ways in which organizations can shield their employees from changing tasks when contractual commitment is not possible. Dessein and Santos (2006) model a trade-off between coordination of tasks in an organization on the one hand and the need to adapt tasks to changing local circumstances on the other. They show that organizational rigidity is optimal when coordination is important and adaptation is not important. Coordination is achieved through specialization and the implementation of tasks according to pre-determined rules, at the expensive of a sub-optimal fit with the changing environment.

Our paper is closely related to the literature on managerial decisions

\footnotetext{
${ }^{6}$ Inderst and Mueller (2007) build a hold-up model along these lines, focusing on the ex post incentive of the firm to change tasks for the sole reason of reducing the rents obtained by the agent. They show that profit-sharing reduces the firm's incentive to exploit the agent's investments.
} 
regarding corporate strategy when employees can make strategy-specific investments. The possibility of a change in strategy makes employees reluctant to invest in strategy-specific projects. Commitment to a particular strategy enhances employees' incentives, at the cost of potentially foregoing profitable opportunities (Rotemberg and Saloner 1994). Rotemberg and Saloner (2000) and Van den Steen (2005) show that managerial vision, modelled as a bias towards a specific strategy, provides employees with more certainty that their strategy-specific investments will pay off. If managers have reputational concerns, public disclosure of strategic plans serves as commitment to a specific strategy (Ferreira and Rezende 2007). Bolton et al. (2013) argue that a CEO's overconfidence regarding the quality of his initial information on the firm's optimal strategy serves as commitment, but may thereby also suppress employees' initiatives that would show the benefits of alternative strategies (see also Wong and Wang 2012). Mailath et al. (2004) consider the interaction between strategy-specific investments, strategy choice, and mergers when a merger makes a change in strategy less likely due to the internalization of negative externalities. Ferreira and Kittsteiner (2014) show that competition can foster commitment to a specific strategy, by reducing the option value of flexibility. ${ }^{7}$ Most of this literature focuses on a single organizational policy aimed at enhancing employees' specific investments. Our contribution integrates several organizational policies, allowing us to analyze the interaction between these policies in affecting investment in specific human capital.

Following Becker (1962), a large literature has developed on firm-specific human capital. As employees' incentives to make costly firm-specific investments are diminished when firms can expropriate (part of) the quasi-rents ex post, a commitment to reward employees' specific investments can be in firms' interests. Organizational responses to the commitment problem include promotions (Prendergast 1993), up-or-out promotion schemes (Kahn and Huberman 1984, Ghosh and Waldman 2010), and employee asset ownership to increase ex post bargaining power (Hart and Moore 1990). This literature does not consider dynamic job design.

\footnotetext{
${ }^{7}$ Schaefer (1998) argues that organizational change leads employees to engage in costly influence activities. This reduces the profitability of change and, hence, brings some degree of inertia. Under the assumption that influence activities are less rewarding when the firm's prospects are worse, Schaefer (1998) predicts that firms are more likely to change when their survival is threatened.
} 


\section{The Commitment Problem}

Consider a principal, who employs an agent for two periods. In period 1 , the agent performs task $A$. The probability that task $A$ is successfully completed equals the effort the agent puts in the task. By normalization, the value of success (failure) to both the agent and the principal equals 1 (0). Consequently, task $A$ yields an expected benefit equal to

$$
U_{1}=e_{1},
$$

where $e_{1}$ denotes the level of effort the agent exerts in period 1 . The cost of first-period effort is equal to $\frac{1}{2 \lambda}\left(e_{1}\right)^{2}$ and is entirely borne by the agent.

At the start of period 1, the principal also makes a decision whether to learn the features of an alternative task, task $B$. This learning can be interpreted as exploration. Let $c$ denote the cost of exploration to the principal. We assume that the agent observes the principal's exploration decision before choosing $e_{1}$. If the principal has explored task $B$ during period 1 , she can assign the worker to either task $A$ or task $B$ in period 2. In period 2, the probability that task $A$ is successfully completed equals $e_{1}+e_{2, A}$, where $e_{2, A}$ is the agent's second-period effort on task $A$. Hence, in period 2 task $A$ yields an expected benefit to both the principal and the agent equal to

$$
U_{2}(A)=e_{1}+e_{2, A}
$$

Task $B$ yields an expected benefit to both the principal and the agent equal to

$$
U_{2}(B)=e_{2, B}+\mu
$$

where $e_{2, B}$ is the agent's second-period effort on task $B$, and $\mu$ is a stochastic term, denoting the productivity of task $B$ relative to task $A$. We assume that $\mu$ is uniformly distributed on $[-h, h]$, such that the expected value $E(\mu)=0$. If the principal decides to explore task $B$, at $\operatorname{cost} c$, the principal learns the exact level of $\mu$ before the start of period 2. Second-period effort cost is also borne by the agent and is independent of the assigned task $T \in\{A, B\}$ : $\frac{1}{2 \lambda}\left(e_{2, T}\right)^{2}$.

In this section, we assume that there are no verifiable performance measures, so that incentive pay is not feasible. We relax this assumption in the next section. To minimize on notation, we assume that the principal and 
the agent both value both periods equally, i.e. their discount rate is zero. The agent's outside-option payoff is zero.

Several features of our model are worth emphasizing. First, the agent's first-period effort is an investment in task-specific productivity. It increases the second-period payoff only when task $A$ is maintained. The initial investment is useless in the second period when the task is replaced. Hence, exploration of task $B$ reduces the probability that the initial investment in task-specific skills are exploited in period 2 .

Second, the assumption that the probability that task $B$ is successfully completed is stochastic while this probability for task $A$ is deterministic is for convenience only. What matters is that in period 2 task $B$ is possibly superior to task $A$, despite the task $A$-specific skills obtained during period 1 . Placing the uncertainty on task $A$ or adding an identically and independently distributed stochastic term to task $A$ does not affect the results. ${ }^{8}$

Third, several interpretations of the two tasks are possible. Task $A$ could be working with the firm's current technology or strategy, while a potential new technology or strategy would require different skills from the agent. The tasks can be seen as different sets of job requirements, with ex ante uncertainty about which job design matches best with the agent's skills. Alternatively, relating to the examples in the Introduction, task $A$ can be a specific project or client, which could be reassigned to a colleague.

Fourth, the principal and the agent are assumed to have the same expected benefit from the agent's effort on either task. As a consequence, there is no disagreement among the principal and the agent regarding the decision to maintain or replace task $A$ after period 1. The agent's benefit could stem from private benefits or intrinsic motivation related to the outcomes of tasks, or it could be interpreted as a reduced-form model of incentive pay linked to the project's success. Assuming that the agent's benefits are proportionally smaller (or larger) than the principal's benefits does not affect the nature of the commitment problem studied in this paper. In Section 4, we will show that allowing for (explicit) incentive pay does not affect the results qualitatively as long as incentives are not perfect.

Fifth, even though the principal's and the agent's benefits from both

\footnotetext{
${ }^{8}$ With stochastic productivity elements on both tasks, realizations could be such that second-period payoffs on either task would be negative. If the agent would leave rather than face a negative second-period payoff, this would provide an upper bound on the degree of commitment possible.
} 
tasks are equal, their preferences regarding effort are not fully aligned as only the agent bears the cost of effort. This implies that the principal prefers the agent to exert more effort than is optimal from the agent's perspective. Important in this respect is that the agent expects to earn a rent, so that the principal does not have to compensate the agent for additional cost of effort. $^{9}$

Lastly, parameters $\lambda$ and $h$ determine the relative importance of exploitation and exploration, and, thereby, the cost and benefits of commitment. A higher level of $\lambda$ implies that the agent's current effort is more responsive to increases in the agent's (current and future) benefits of current effort. On the other hand, higher levels of $h$ correspond to higher expected benefits from exploration, as the probability that task $B$ is superior to task $A$ in period 2 increases in $h$.

The timing is as follows. Before period 1, nature draws the realization of the stochastic productivity difference between tasks, $\mu$, unobserved by the principal and the agent. In period 1, the principal first makes a decision whether or not to explore task $B$. Next, the agent observes the principal's decision and works on task $A$. If the principal explored task $B$, she learns $\mu$ and decides on second-period task assignment. The agent works on the task assigned to him. If the principal did not explore task $B$, the agent performs task $A$ in period 2. Finally, payoffs are realized.

Throughout, we make the following two assumptions on parameter values. The first assumption ensures that both with and without commitment in equilibrium the probability that task $A$ is maintained after exploration in the first period is strictly smaller than 1 . Effectively, this precludes situations where exploration cannot lead to the discovery of a more productive task or technology. Combined with the first assumption, the second assumption ensures that the equilibrium probability of project success is always smaller than 1.

Assumption 1: $4 \lambda<h$.

Assumption 2: $\lambda+h<1$.

We solve the game by backward induction. First, consider the effort

\footnotetext{
${ }^{9}$ With a perfect performance measure, the agent can be kept on his participation constraint, implying that the principal effectively bears the cost of effort. In our model, as in any moral hazard setting, perfect incentives render other means of incentivization useless. This also implies that if the principal exerts effort herself rather than delegating this to an agent, commitment would not be beneficial to the principal.
} 
decision of the agent in period 2. Irrespective of the principal's secondperiod task assignment, the agent exerts $e_{2, T}=\lambda$.

Next, consider the principal's decision on task assignment. If initially the principal did not explore task $B$, the agent performs task $A$ by assumption. Suppose that the principal explored task $B$. Then, when making the taskassignment decision, she knows $e_{1}$ and $\mu$. Moreover, she anticipates that in period 2 the agent will choose $e_{2, T}=\lambda$ regardless of task assignment. Hence, it is optimal for the principal to keep task $A$ if and only if $U_{2}(A)>U_{2}(B)$ as given by (2) and (3), respectively. This implies that the principal keeps task $A$ if $\mu<e_{1}$. From an ex ante perspective, the probability that task $A$ will be maintained in period 2 equals $\pi=\frac{1}{2 h}\left(h+e_{1}\right)$, where Assumption 1 ensures that in equilibrium $\pi<1$.

Now consider the agent's effort decision in period 1. First, if the principal explores task $B$, the agent's expected payoff equals

$$
\begin{aligned}
E\left[U_{1}+U_{2}-\frac{1}{2 \lambda}\left(e_{1}\right)^{2}-\frac{1}{2 \lambda}\left(e_{2}\right)^{2}\right]= & e_{1}-\frac{1}{2 \lambda}\left(e_{1}\right)^{2}+\frac{h+e_{1}}{2 h}\left(e_{1}+\lambda\right)+ \\
& +\frac{h-e_{1}}{2 h}\left(\lambda+\frac{h+e_{1}}{2}\right)-\frac{1}{2} \lambda .
\end{aligned}
$$

Differentiating (4) with respect to $e_{1}$ and solving the first-order condition yield optimal effort $\tilde{e}_{1}$ :

$$
\tilde{e}_{1}=\frac{3 h \lambda}{2 h-\lambda} .
$$

Effort increases in $\lambda$, the inverse of the cost of effort function, reflecting the agent's responsiveness to incentives. Effort decreases in $h$, as the probability that task $A$ is maintained is decreasing in $h$. Substituting (5) into the probability of keeping task $A$ as given by $\pi=\frac{1}{2 h}\left(h+e_{1}\right)$ yields

$$
\tilde{\pi}=\frac{h+\lambda}{2 h-\lambda} .
$$

Using (5) and (6), we can write equilibrium effort as $\tilde{e}_{1}=\lambda(1+\tilde{\pi})$. This expression clearly illustrates that period 1 effort depends on the probability that the principal maintains task $A$ in period 2. In other words, the agent's effort depends on his expectation of future task assignment. Second, it is easily verified that if the principal does not engage in exploration, the agent optimally sets $e_{1}=2 \lambda$.

Let us finally consider the principal's exploration decision. It follows 
from the analysis above that if the principal explores task $B$, her ex ante expected payoff equals

$$
E\left[U_{1}+U_{2}\right]-c=\frac{h^{3}+12 h^{2} \lambda-6 h \lambda^{2}+\lambda^{3}}{(2 h-\lambda)^{2}}-c .
$$

If the principal does not explore task $B$, the agent's efforts yield a payoff to the principal equal to $5 \lambda$. Comparing this to (7), it follows that exploring task $B$ yields a higher payoff to the principal than not exploring task $B$ if

$$
c<\frac{\left(h^{2}-6 h \lambda+2 \lambda^{2}\right)(h-2 \lambda)}{(2 h-\lambda)^{2}} .
$$

Equation (8) defines the range of parameters for which the principal chooses to explore task $B$. Not surprisingly, if the cost of exploration are too large, the principal refrains from exploring. More interestingly, using Assumption 1, it is easily derived that there exists ranges of $h$ and $\lambda$ for which the principal chooses not to explore task $B$ even when $c=0 .{ }^{10}$ The explanation for this result is that by not exploring task $B$, the principal induces the agent to expend more effort in period 1. To put it differently, the probability that task $A$ will be replaced in period 2 discourages the agent to invest in task $A$. As we discuss below, the principal faces a commitment problem when engaging in exploration. Abstaining from exploration can be seen as a device to alleviate - but not eliminate - the commitment problem.

The key feature of our game is the presence of a time-inconsistency problem in case of exploration. Once $e_{1}$ is fixed, it is best to maintain task $A$ if $\mu<e_{1}$. The problem is that this ex post optimal replacement decision does not take the effect on the agent's first-period effort into account. To determine the ex ante optimal replacement decision, suppose that an exploring principal can commit herself to keep task $A$ if $\mu<z$. Proposition 1 gives the main result of the base model.

Proposition 1 Given the decision to explore task B, the principal faces a time-inconsistency problem: ex ante the principal wants to commit herself to keeping task $A$ for values of $\mu$ for which ex post she wants to replace task A. The benefit of commitment equals $\frac{(3 h \lambda)^{2}}{4(h-\lambda)(2 h-\lambda)^{2}}>0$, and decreases in $h$ and increases in $\lambda$.

\footnotetext{
${ }^{10}$ This occurs if $\lambda>\left(\frac{3}{2}-\frac{1}{2} \sqrt{7}\right) h$.
} 
Proof. Given that task $A$ is maintained if $\mu<z$, the agent anticipates that with probability $\pi^{C}=\frac{1}{2 h}(h+z)$ he will continue working on task $A$ in period 2. Therefore, first-period effort results from maximizing

$$
\begin{aligned}
E\left[U_{1}+U_{2}-\frac{1}{2 \lambda}\left(e_{1}\right)^{2}-\frac{1}{2 \lambda}\left(e_{2}\right)^{2}\right]= & e_{1}-\frac{1}{2 \lambda}\left(e_{1}\right)^{2}+\frac{h+z}{2 h}\left(e_{1}+\lambda\right)+ \\
& +\frac{h-z}{2 h}\left(\lambda+\frac{1}{2}(h+z)\right)-\frac{1}{2} \lambda
\end{aligned}
$$

with respect to $e_{1}$, yielding optimal effort $e_{1}^{C}=\lambda\left[1+\frac{h+z}{2 h}\right]$. The agent's effort is increasing in $z$, as the probability that the agent works on task $A$ increases in $z$. The principal's total expected payoff can now be written as

$$
E\left(U_{1}+U_{2}\right)=e_{1}^{C}+\frac{h+z}{2 h}\left(e_{1}^{C}+\lambda\right)+\frac{h-z}{2 h}\left(\lambda+\frac{1}{2}(h+z)\right) .
$$

Maximizing (9) with respect to $z$ gives the ex ante optimal replacement decision to keep task $A$ if $\mu<z^{C}=\frac{3 h \lambda}{h-\lambda}$. This yields

$$
e_{1}^{C}=\frac{3 h \lambda}{2 h-2 \lambda}>\tilde{e}_{1}
$$

and

$$
\pi^{C}=\frac{h+2 \lambda}{2 h-2 \lambda}>\tilde{\pi}
$$

where $\tilde{e}_{1}$ and $\tilde{\pi}$ are given by (5) and (6), respectively. As $z^{C}>e_{1}^{C}$, it is possible that task $A$ is maintained even though task $B$ would yield moderately higher payoff. Substituting for $z^{C}$ into the principal's payoff under commitment (9) yields

$$
E\left[U_{1}+U_{2}\right]=\frac{h^{2}+12 h \lambda-4 \lambda^{2}}{4(h-\lambda)} .
$$

Comparing the principal's payoff of exploration with commitment (10) to the payoff of exploration without commitment (7), we obtain

$$
E_{\text {commitment }}\left[U_{1}+U_{2}\right]-E_{\text {no commitment }}\left[U_{1}+U_{2}\right]=\frac{(3 h \lambda)^{2}}{4(h-\lambda)(2 h-\lambda)^{2}}>0 .
$$

This expression decreases in $h$ and increases in $\lambda$.

Commitment yields higher payoff to the principal. This is despite the 
fact that $z^{C}>e_{1}^{C}$ : the principal commits to maintaining task $A$ for values of $\mu$ for which she ex post prefers to replace task $A$. The explanation for this finding is as follows. In determining for which values of $\mu$ to keep the agent on task $A$, the principal faces a trade-off. On the one hand, firstperiod effort increases in the probability that the agent works on task $A$ in period 2, which in turn increases in the range of values of $\mu$ for which the principal commits to keep task $A$ (i.e. in $z$ ). On the other hand, a higher $z$ increases the expected cost that arises from the possibility that task $A$ is maintained while task $B$ is more productive. The latter cost of an increase in $z$ is zero starting from the situation without commitment, while the additional effort that follows from an increase in $z$ is a first-order benefit. Hence, commitment is always beneficial to the principal. The optimal level of $z$ balances the benefit of additional effort with the increase in the expected loss from maintaining relatively unproductive activities.

Crucial for Proposition 1 is that the additional cost of effort are borne by the agent, not by the principal. This disalignment gives rise to all results in this paper. If the principal would bear the full cost of effort or, equivalently, if the principal and the agent would be the same person, the outcome with commitment would be the same as the outcome without commitment.

The comparative statics in Proposition 1 can be explained as follows. Optimal commitment increases the probability that task $A$ is maintained, which gives incentives to the agent to exert extra effort. As $\lambda$ measures the responsiveness of the agent's effort to incentives, these benefits of commitment increase with $\lambda$. Parameter $h$ reflects the degree of uncertainty on the optimal second-period task assignment, with the probability of a change in task increasing in $h$. For larger values of $h$, the principal needs to commit to maintaining task $A$ is for an even larger range of realizations of $\mu$, where maintaining task $A$ is even more sub-optimal, in order to obtain a given increase in the probability of maintaining task $A$. Hence, commitment is less effective for larger values of $h$, implying that the value of commitment is smaller in more volatile environments. This corresponds to predictions in the literature on organizational change and inertia (Hannan and Freeman 1984, March 1991) as well as to empirical findings (Miller and Chen 1994).

Now consider the principal's exploration decision given commitment. A comparison between the principal's payoff under exploration (10) and the principal's payoff without exploration - which equals $5 \lambda-$, shows that ex- 
ploring task $B$ yields a higher payoff if

$$
c<\frac{(h-4 \lambda)^{2}}{4(h-\lambda)} .
$$

Corollary 1a follows from comparing (8) and (11).

Corollary 1a Under commitment, exploration occurs for a wider range of parameters.

In the absence of commitment power, abstaining from exploration can be seen as a commitment device, increasing the agent's first-period effort. However, this comes at the cost of a potentially sub-optimal second-period task assignment. Commitment power would give the principal the possibility to engage in exploration while reducing - but not eliminating - the probability that exploration induces a change in task. This allows for a better balance between the cost and benefits of exploration, making exploration attractive in more situations. In particular, expression (11) shows that with commitment power, exploration is always optimal if exploration $\operatorname{cost} c=0$, in contrast to the situation without commitment.

In many situations, commitment is not possible. The (expected) benefit of tasks and the realization of ex ante uncertain benefit-relevant variables are often not verifiable, so that contracting is not feasible. Moreover, if the realization of $\mu$ is such that $e_{1}^{C}<\mu<z^{C}$, both the principal and the agent would benefit from renegotiating a contract that stipulates continuing with task $A$. In the remainder of this paper, we consider several organizational policies that can reduce the time-inconsistency problem in the absence of commitment power. In the next section, we consider the combined merit of task-specific investments by the principal, organizational missions, and incentive pay. We first revisit the possibility to abstain from exploration altogether in the following Corollary, which follows from equation (8).

Corollary $1 \mathrm{~b}$ In the absence of commitment power, abstaining from exploration can be beneficial to the principal. The benefits of refraining from exploration increase in $\lambda$ and decrease in $h$.

The take-away from Corollary $1 \mathrm{~b}$ is that organizations are sometimes better off refraining from pursuing innovations. While innovations in technology, strategy, or job design can bring higher productivity, the prospect of these possible innovations reduce employees' investments in skills specific 
to their current tasks. ${ }^{11}$ In the management literature, the fundamental trade-off between exploiting current skills and knowledge on the one hand and exploring new alternatives on the other has been extensively discussed following March (1991). The typical stance in the management literature is that balancing both activities (being 'ambidextrous') is difficult but necessary (Benner and Tushman 2003, Greve 2007, Lavie et al. 2009). Gupta et al. (2006) argue, in line with our findings here, that some organizations may be better off specializing in the exploitation of current activities, in particular when operating in a stable environment. Corollary $1 b$ is in line with the evidence provided by Uotila et al. (2008), who use data on S\&P 500 firms to show that in industries with low R\&D intensity (arguably corresponding to a low $h$ in our model), firm performance is decreasing in exploration. In industries with high $\mathrm{R} \& \mathrm{D}$ intensity, the relation between exploration and performance is hump-shaped.

\section{Organizational responses to the commitment prob- lem}

The previous section has shown that if task-specific investment and exploration are both sufficiently important, the principal suffers from a commitment problem. In this section, we discuss three ways in which organizations can mitigate the commitment problem. First, we allow the principal to make initial investments that have a lasting effect on the likelihood of success when the agent performs task $A$. Second, we allow the principal and the agent to have biased preferences for task $A$. Third, we allow the principal to use monetary incentives to boost the agent's effort in period 1. We first describe the three extensions separately, and then integrate them jointly into the model to determine the optimal mix of organizational policies. Throughout most of this section, we assume that the principal explores task $B$ during the first period. We revisit the question whether it is optimal to engage in exploration at the end of this section.

\footnotetext{
${ }^{11}$ An alternative interpretation of Corollary $1 \mathrm{~b}$ is that credibly refraining from evaluating employees' current task performance can give extra incentives to increase learning-bydoing. Provided that in the absence of evaluation employees keep the same tasks, this makes employees certain that their current efforts have long-lasting benefits.
} 


\subsection{Extension 1: (Over-)investment in task-specific produc- tivity}

In the basic model, all investments in task-specific human capital were made by the employee. However, firms may also be able to make task-specific investments. For instance, equipment can be fine-tuned to a particular technology or task. Alternatively, the firm can offer or pay for task-specific training of the employee, or facilitate bonding between employees and clients. Insofar as the cost and benefits of such investments fall into the same period, it has no effect on the time-inconsistency problem that we consider in this paper. However, when the firm's current task-specific investment has effects that last into future periods, it affect the employee's ex post optimal task assignment and thereby the employee's own task-specific investment.

We extend the basic model by assuming that the principal can make a task $A$-specific investment $I$ at the beginning of period 1 . This investment is made before the agent exerts effort and can be observed by the agent. Investing $I$ yields a cost to the principal in the first period equal to $\frac{1}{2 \theta} I^{2}$. Investing increases the probability of success in the second period by $I$, but only if the agent works on task $A$ in period $2 .{ }^{12}$ Note that there is no direct complementarity between the principal's and the agent's investment in task-specific productivity; all effects on the agent's effort run through the larger probability of maintaining task $A$ after period 1 . This implies that the principal's and agent's expected benefit from task $A$ in period 2 are given by:

$$
U_{2}=I+\sum_{1}^{t} e_{t, A}
$$

As the principal's investment increases the probability of success when using task $A$ in period 2, we need to modify Assumption 1 to ensure that exploration can discover an alternative that is superior to task $A$ :

Assumption 1a: $4 \lambda+\theta<h$.

\footnotetext{
${ }^{12}$ For tractability, we assume linear benefits and convex cost of investment, rather than the -arguably more natural - assumptions of concave benefits and linear cost. Results are qualitatively similar. Similarly, assuming that the principal's investments also has a return in the first period does not affect our results but makes the analysis less transparent.
} 


\subsection{Extension 2: An Idealistic (or Persistent) Principal}

"Having a sense of mission is the chief way by which managers overcome the problem of shirking in organizations" Wilson (1989, p. 95)

Wilson (1989) forcefully argues that having a mission can be useful for organizations to motivate agents. Illustrative is his account on the way J. Edgar Hoover shaped the Federal Bureau of Investigation in the twenties of the previous century. The definitions of the jobs of FBI agents, the personnel system, and the training academy were organized in such a way that each FBI agent exactly knew what was expected of him, then and later. The cost of having a mission is loss of flexibility. Employees may resist new tasks insofar these do not contribute to the organization's mission. Moreover, a mission may obstruct adequate responses of the organization to changes in the environment. According to Wilson (1989), the effects of a mission depend crucially on the extent to which employees internalize the mission. In this spirit, Besley and Ghatak (2005) show that missionmotivated agents need weaker monetary incentives. In contrast, Rotemberg and Saloner (2000) and Van den Steen (2005) argue that managerial vision, reflecting strong or biased beliefs about the right strategy of the firm, also motivates employees who do not share the manager's vision.

We extend the basic model to analyze whether an organizational mission can help to alleviate the time-consistency problem identified in the previous section. We define an organization's mission as a preference of the principal and the agent for a given course of action. We model an organization's mission as a strict preference on the side of the principal for task $A$. Specifically, we assume that at the beginning of period 2 the principal assigns task $A$ to the agent if the following condition holds:

$$
U_{2}(A)-U_{2}(B)=p+I+\sum_{1}^{t=2} e_{t, A}-e_{2, B}-\mu>0,
$$

where $p>0$ is the principal's predisposition towards task $A$. The parameter $p$ reflects an intrinsic preference for task $A$ or reflects that the principal receives higher perks if task $A$ is chosen. This is akin to mission preferences as in Besley and Ghatak (2005), see also Francois (2007). If the principal is unbiased herself, she can achieve the same effects by delegating the decision on task assignment after period 1 to a third person with predisposition $p$, 
as in Rotemberg and Saloner (2000) and Van den Steen (2005).

The extent to which the organizational mission is internalized by the agent is modeled as a preference of the agent for working on task $A$ equal to $\alpha p$, with $0 \leq \alpha \leq 1 .{ }^{13}$ The agent's expected benefit from working on task $A$ in period 2 equals

$$
U_{2}^{A}=\alpha p+I+\sum_{1}^{t=2} e_{t, A}
$$

\subsection{Extension 3: Incentive pay}

The basic model showed that the principal's lack of commitment results in sub-optimally low effort in the first period. So far, we have abstained from explicit monetary incentives. This third extension analyzes whether the principal can overcome the time-inconsistency problem by introducing incentive pay, in a limited liability setup. As we will show, incentives mitigate but do not eliminate the commitment problem.

We assume that at the beginning of the game the principal offers the agent a contract, consisting of (1) a base wage $w_{t}$ in each period, and (2) a bonus $F$ if $A$ has been successfully completed in period $1 .{ }^{14}$ We assume that the agent's outside-option payoff is zero and that he is protected by limited liability. The implication is that the payment in each period must be nonnegative. It follows directly that the optimal contract from the perspective of the principal has a zero base wage in both periods, $w_{t}=0$. Important to note is that through the assumption of limited liability, the cost of providing incentive pay to the principal exceeds the cost of effort of the agent. Hence, the agent earns a rent. The introduction of incentive pay into the model implies that $U_{1}^{A}=\alpha p+e_{1}(1+F)$ and $U_{1}=p+e_{1}(1-F) .{ }^{15}$

\footnotetext{
${ }^{13}$ This specification implies that we neglect the possibility that the agent is intrinsically motivated to work on task $A$, independent of the organizational mission. It is straightforward to show that an intrinsic motivation to work on task $A$ leads to higher first-period effort.

${ }^{14} \mathrm{We}$ focus on incentive pay as a means to increase first-period effort. A bonus for success in the second period also provides incentives for effort in the first period, but in the current setting, first-period and second-period bonuses are substitutes. We assume here that success of task $A$ is verifiable. Instead, we could also have assumed that the principal's task assignment is verifiable. By making the bonus dependent on the taskassignment decision, we would introduce another distortion into the model. The manager would have an incentive to assign task $B$ to avoid giving a bonus (see Rotemberg and Saloner, 1993).

${ }^{15}$ We keep the intrinsic preference for success of the agent here to facilitate the comparison with the previous sections. None of the results in this section changes qualitatively
} 


\subsection{Analysis}

The optimal combination of organizational policies aimed at alleviating the time-inconsistency problem can be found by taking the same steps as in the previous section. Irrespective of $p, \alpha, I$, and $F$, in period 2 the agent will choose $e_{2, T}=\lambda$ for $T=\{A, B\}$. The probability that a biased principal with predisposition $p$ keeps the agent on task $A$ equals the probability that $\mu<p+I+e_{1}(p, \alpha, I, F)$, which is equal to

$$
\pi^{*}=\frac{1}{2 h}\left[h+p+I+e_{1}(p, \alpha, I, F)\right] .
$$

Clearly, if $p$ and $I$ are sufficiently large, the principal keeps task $A$ for any realization of $\mu$. Assumptions 1a and 2 ensure that in equilibrium $\pi^{*}<1$. First-period effort results from maximizing the agent's expected payoff

$$
\begin{aligned}
& U^{A}=\alpha p+e_{1}(1+F)-\frac{1}{2 \lambda}\left(e_{1}\right)^{2}+\pi^{*}\left(\alpha p+I+e_{1}+\lambda\right)+ \\
& +\left(1-\pi^{M}\right)\left(\lambda+\frac{1}{2}\left(h+p+I+e_{1}\right)\right)-\frac{1}{2} \lambda
\end{aligned}
$$

with respect to $e_{1}$, yielding

$$
e_{1}^{*}(p, \alpha, I, F)=\frac{(3 h+\alpha p+I+2 h F) \lambda}{2 h-\lambda} .
$$

Effort increases in bonus $F$, which is not surprising. Effort also increases in $I$. The principal's task-specific investment makes task $A$ more valuable in period 2, which increases the probability that task $A$ is maintained. Together, these effects imply that the agent's incentive to exert effort in period 1 increases in $I$.

To understand the effect of $p$ on effort three effects have to be distinguished. First, a more biased principal is more likely to keep the worker on task $A$, which makes it more rewarding to make task-specific investments. Second, a more biased principal continues less rewarding tasks. The secondperiod payoff to the agent when his marginal unit of effort makes that task $A$ is kept (makes the principal indifferent between the tasks) is decreasing in $p$, which reduces the agent's incentive to invest in task $A$. These two effects

when the agent is assumed to derive less private benefits from successful implementation of the task than the principal. While smaller private benefits for the agent increase the scope for incentive pay, commitment always increases the principal's payoff. 
of $p$ on $e_{1}$ cancel out. ${ }^{16}$ Third, an agent who shares the principal's mission wants to continue working on the task. This motivates him to expend high effort. This positive effect of $p$ on effort implies that the organization's mission statement is partially a self-fulfilling prophecy: the increased effort of the agent makes it even more likely that the organization will continue with its stated tasks. However, the bias of the principal comes at the cost of a distorted task choice at the beginning of period 2. Both aspects are in line with Wilson (1989)'s observations on the consequences of missions in public organizations when discussing the effects of changes imposed by external actors: "Resistance to innovation is all the stronger when the members of the organization are endowed with a strong sense of mission that enjoys substantial support..." (p. 221-222). A proper mission motivates employees insofar these have adopted the mission, but it also reduces flexibility.

We are now ready to determine the optimal investment $\hat{I}$, mission, $\hat{p}$, and bonus, $\hat{F}$. Assuming that the principal's predisposition is not a part of total surplus, the optimal values of $p, I$, and $F$ are given in the following proposition. ${ }^{17}$

Proposition 2 The optimal combination of the firm's task-specific investment, organizational mission, and incentive pay is given by

$$
\begin{aligned}
& \hat{I}=\frac{\theta h\left(4 h+\left(9-\alpha^{2}\right) \lambda\right)}{2 h\left(4 h-\left(3+\alpha^{2}\right) \lambda\right)-\theta\left(4 h+\left(1-\alpha^{2}\right) \lambda\right)}>0, \\
& \hat{p}=\frac{4 \alpha \lambda h(3 h-\theta)}{2 h\left(4 h-\left(3+\alpha^{2}\right) \lambda\right)-\theta\left(4 h+\left(1-\alpha^{2}\right) \lambda\right)} \geq 0,
\end{aligned}
$$

and

$$
\hat{F}=\frac{\lambda(3 h-\theta)\left(1-\alpha^{2}\right)}{2 h\left(4 h-\left(3+\alpha^{2}\right) \lambda\right)-\theta\left(4 h+\left(1-\alpha^{2}\right) \lambda\right)} \geq 0 .
$$

\footnotetext{
${ }^{16}$ In the Appendix, we show that if $\mu$ is not uniformly distributed and the principal is more biased than the agent $(\alpha<1)$, the two effects may not fully cancel out. In particular, if the density of $\mu$ is strictly decreasing over the interval $[0, h]$, there is an additional positive effect of $p$ on effort from the fact that higher effort decreases the probability of continuation of the less rewarding task.

${ }^{17}$ We assume here that investment $I$ and the bonus $F$ are determined by a neutral (super)principal. If, instead, these would be set by a biased principal, it is straightforward to show that both $I$ and $F$ are set at a higher level. Provided that the cost of investment and bonus pay fall on the neutral (super-)principal, this reduces the optimal level of biased principal's predisposition.
} 
Proof. Maximizing the principal's expected payoff as given by

$$
\begin{aligned}
& E\left[U_{1}+U_{2}\right]=e_{1}^{*}(p, \alpha, I, F)(1-F)-\frac{1}{2 \theta} I^{2}+\pi^{*}\left[I+e_{1}^{*}(p, \alpha, I, F)+\lambda\right]+ \\
& \left(1-\pi^{*}\right)\left(\lambda+\frac{1}{2}\left[h+p+I+e_{1}^{*}(p, \alpha, I, F)\right]\right)
\end{aligned}
$$

with respect to $p, I$, and $F$, with $\pi^{*}$ given by (12) and $e_{1}^{*}(p, \alpha, I, F)$ by (13), yields first-order conditions

$$
\begin{gathered}
I=\frac{\theta\left(2 h^{2}-(1-F) \lambda^{2}+4 h \lambda+\alpha p \lambda\right)}{(2 h-\lambda)^{2}-2 h \theta}, \\
p=\frac{\lambda \alpha\left(6 h^{2}+2 h I-4 F h(h-\lambda)\right)}{(2 h-\lambda)^{2}-\alpha^{2} \lambda^{2}},
\end{gathered}
$$

and

$$
F=\frac{3 h \lambda-2 \alpha p(h-\lambda)+\lambda I}{2 h(4 h-3 \lambda)}
$$

respectively. Solving this system of three equations yields the expressions for $\hat{I}, \hat{p}$, and $\hat{F}$.

Before further discussing the implications of Proposition 2, it is useful to discuss how each of the three organizational policies works in isolation. We first focus on the optimal organizational mission $p$. Assuming that $I=0$ and $F=0$, rewriting (19) gives

$$
p^{*}=\frac{6 h^{2} \alpha \lambda}{(2 h-\lambda)^{2}-\alpha^{2} \lambda^{2}} .
$$

Assumption 1a guarantees that $p^{*}>0$ for any $\alpha>0$. Proposition 3 follows.

Proposition 3 Assuming that $I=0$ and $F=0$, the optimal predisposition $p^{*}$ is given by (21), which is positive if and only if $\alpha>0 . p^{*}$ increases in $\alpha$ and $\lambda$ and decreases in $h$. The organizational mission fully resolves the commitment problem only when $\alpha=1$.

Proof. The comparative statics of $\alpha, \lambda$, and $h$ follow directly from (21). Substituting for $p, I=0$, and $F=0$ into the principal's expected payoff (17) with $\pi^{*}$ given by (12) and $e_{1}^{*}(p, \alpha, I, F)$ by (13) and subtracting this from the principal's expected payoff under commitment as given by (10) 
gives

$$
\frac{9(1-\alpha)(1+\alpha) h^{2} \lambda^{2}}{4(h-\lambda)(2 h-\lambda-\alpha \lambda)(2 h-\lambda+\alpha \lambda)} \geq 0
$$

which is equal to zero only when $\alpha=1$.

Proposition 3 shows that the commitment problem can be reduced by delegating the decision on second-period task choice to a person biased in favor of maintaining the task. This organizational mission (or biased view of the principal) induces the agent to exert more effort in the first period, but only when the agent (partially) internalizes the mission. The additional effort, in turn, further increases the probability that the principal maintains task $A$. However, the mission comes at the cost of keeping tasks that objectively should be replaced. ${ }^{18}$ The optimal mission has the same effect as commitment only if it is fully shared by the agent, i.e. when $\alpha=1$. For $\alpha<1$, the mission is less effective in inducing the agent to exert additional first-period effort as compared to optimal commitment based on the realization of $\mu$ as discussed in Section 3. This difference can be explained as follows. Both under commitment and under a partially internalized mission, task $A$ is sometimes maintained while the agent wants the task to be replaced after period 1 . The agent prefers to reduce this possibility, which is possible under commitment as higher effort reduces the range of realizations of $\mu$ for which task $A$ is maintained ex post while task $B$ yields higher payoff. In case of a partially internalized mission, however, effort is less rewarding as higher effort implies that the task is maintained for even lower realizations of $\mu$. Hence, the agent exerts more effort under optimal commitment as compared to a partially internalized organizational mission.

The results in Proposition 3 correspond to Beckman (2006), who shows that if the founding team of a young firm is more homogenous in terms of prior work affiliations, the firm puts more emphasis on exploitation. Founding teams with diverse background are more likely to engage in exploration. More diversity may bring lower agreement on the right course of action, yielding more explorative activities. In terms of our model, a more homogenous team is less likely to change course due to shared (but possibly mistaken) belief in current activities. This facilitates exploitation.

In earlier work on managerial vision, Rotemberg and Saloner (2000) and

\footnotetext{
${ }^{18}$ It follows that the organization (i.e. the neutral principal) would like to replace the biased manager after the agent has chosen his first-period effort. Hence, the delegation of the task choice (or the organizational mission) should be credible and irreversible.
} 
Van den Steen (2005) show that an unbiased principal can benefit from delegating project choice to a manager biased in favour of a certain type of projects. In both papers, a strong or biased belief of the manager about the future state of the organization encourages employees to work hard on projects that are in line with the manager's vision, even when they do not share the manager's vision. In contrast to these papers, employees in our model do not only care about whether their project is implemented, but also about the success of the implemented project. This implies that managerial vision by itself does not motivate employees, as the effect of managerial vision is to continue projects that should be replaced, which is demotivating. In line with Wilson (1989), only when the vision is adopted by the employees does it have positive effects on employee effort. Our model shares with Van den Steen (2005) that an organization with a specific vision is particularly attractive to employees who share that vision, corresponding to a high $\alpha$ in our model. Besley and Ghatak (2005) have a similar finding regarding mission preferences, and further show that workers who share an organization's mission need weaker incentive pay to provide effort, in a framework without task-specific investments and task-replacement. It follows from (19) that missions and incentive pay are also substitutes in our framework, as discussed in Corollary 2a below.

Next, let us focus on the principal's task-specific investment. In the absence of organizational missions and incentive pay, the optimal level of investment is given by (18) with $p=0$ and $F=0$. This yields

$$
I^{*}=\frac{2 h \theta(h+2 \lambda)}{(2 h-\lambda)^{2}-2 h \theta},
$$

where Assumption 1a ensures that $I^{*}>0$. The next proposition shows that $I^{*}$ is larger than the optimal level in the absence of the time-inconsistency problem.

Proposition 4 Assuming that $p=0$ and $F=0$, the principal's optimal task A-specific investment $I^{*}$ is given by (22). $I^{*}$ increases in $\theta$ and $\lambda$ and decreases in $h$. This level of $I^{*}$ is beyond the optimal level of investment when the agent's effort would be fixed at its equilibrium level.

Proof. The comparative statics of $\alpha, \lambda$, and $h$ follow directly from (22). Substituting for $I^{*}, p=0$, and $F=0$ into the agent's effort (13) yields 
$\bar{e}=\frac{\lambda h\left(3(2 h-\lambda)^{2}-4 \theta(h-\lambda)\right)}{(2 h-\lambda)^{2}-2 h \theta}$. Fixing employee effort at $\bar{e}$, the optimal investment is given by maximizing the principal's expected payoff (17) with $\pi^{*}$ given by (12), $e=\bar{e}$, and $p=F=0$ with respect to $I$, which gives $I=\frac{\theta(h+\bar{e})}{2 h-\theta}$. Subtracting this level of $I$ from the optimal level $I^{*}$ and substituting for $\bar{e}$ yields

$$
-\frac{2 h \theta \lambda}{(2 h-\lambda)^{2}-2 h \theta} \frac{6 h^{2}-h \lambda-2 h \theta-\lambda^{2}}{(2 h-\theta)(2 h-\lambda)}<0,
$$

where the inequality follows from Assumption 1a.

The principal will use the opportunity to invest in task $A$ 's second period productivity even when the employees' effort would not respond to the investment, simply because it directly raises the probability of success in the second period. However, Proposition 4 shows that the timeinconsistency problem leads the principal to choose an even higher investment level. Thereby, it is more likely that task $A$ will be maintained, which makes it more likely that the agent's first-period efforts also have a secondperiod payoff. It follows that firm's and employees' task-specific investments are complements, even when there is no direct complementarity in the production function.

The optimal level of investment is higher when investment cost are lower (higher $\theta$ ), which is not surprising. $I^{*}$ increases in $\lambda$, for two reasons. First, a high level of $\lambda$ implies a larger level of effort. This yields a higher probability that task $A$ is maintained, increasing the likelihood that the principal's investment pays off. This effect also arises in the absence of the time-inconsistency problem. Second, a high level of $\lambda$ implies a larger responsiveness of effort to additional benefits of effort, which increases the marginal benefit of extra investment. The effects of $h$ are similar: a high $h$ implies a low probability of maintaining task $A$, both directly and through lower effort. It also implies that the agent has a weaker response to increases in $I$, as it only has a small effect on the probability of maintaining task $A$.

Lastly, we focus on the use of incentive pay to alleviate the commitment problem. In the absence of organizational missions and the principal's taskspecific investment, the optimal level of bonus $F$ for first-period success is given by (20) with $p=0$ and $I=0$, which yields

$$
F^{*}=\frac{3 \lambda}{2(4 h-3 \lambda)}>0 \text {. }
$$


This yields Proposition 5.

Proposition 5 Assuming that $p=0$ and $I=0$, the optimal bonus $F^{*}$ is given by (23). $F^{*}$ increases in $\lambda$ and decreases in $h$. The use of incentive pay reduces but does not eliminate the commitment problem.

Proof. The comparative statics of $\lambda$ and $h$ follow directly from (23). Substituting for $F^{*}$ and $p=I=0$ into the principal's expected payoff (17) with $\pi^{*}$ given by (12) and $e_{1}^{*}(p, \alpha, I, F)$ by (13) yields

$$
E\left[U_{1}+U_{2}\right]=\frac{4 h^{2}+49 h \lambda-12 \lambda^{2}}{4(4 h-3 \lambda)} .
$$

Subtracting this from the principal's expected payoff without incentives as given by (7) yields

$\frac{h^{3}+12 h^{2} \lambda-6 h \lambda^{2}+\lambda^{3}}{(2 h-\lambda)^{2}}-\frac{4 h^{2}+49 h \lambda-12 \lambda^{2}}{4(4 h-3 \lambda)}=-\frac{9 h \lambda^{3}}{4(2 h-\lambda)^{2}(4 h-3 \lambda)}<0$,

while comparing it to the principal's expected payoff under commitment as given by (10) gives

$$
\frac{h^{2}+12 h \lambda-4 \lambda^{2}}{4(h-\lambda)}-\frac{4 h^{2}+49 h \lambda-12 \lambda^{2}}{4(4 h-3 \lambda)}=\frac{9 h \lambda^{2}}{4(h-\lambda)(4 h-3 \lambda)}>0,
$$

where the inequalities follows from Assumption 1a.

Incentive pay yields benefits through higher first-period effort, which also generates extra payoff in the second period if task $A$ is maintained. ${ }^{19}$ The expected cost of incentive pay depends on the probability that the bonus is actually paid out, i.e. on the probability of first-period success. Given our assumption of limited liability on the side of the agent, the more effort the agent exerts in the absence of incentive pay, the higher the cost of incentive pay. Hence, the optimal bonus balances between providing additional incentives for effort and paying for infra-marginal units of effort.

Proposition 5 shows that incentive pay does not fully resolve the commitment problem. Like commitment, incentive pay increases first-period effort. However, the cost of incentive pay is larger than the cost of commitment (provided that it would be possible to commit). Starting from the outcome

\footnotetext{
${ }^{19}$ It is easily shown that if there would be no second period (or first-period effort would have no second-period benefits), the optimal bonus $F=0$.
} 
of the base model, commitment only yields a second-order cost to the principal. Incentives, by contrast, yield a strictly positive cost to the principal, as the limited liability constraint implies that providing incentives to the agent yields a rent to the agent. Moreover, the cost of commitment decreases due to the additional effort provided, whereas the cost of incentive pay increases in effort. A direct implication is that if incentive pay and commitment would both be possible, the principal would only use commitment to incentivize the agent.

The comparative statics in Proposition 5 can be explained as follows. A large $\lambda$ implies that the agent's effort is very responsive to incentives, increasing the benefits of incentive pay. However, it also yields high effort in the absence of incentive pay, implying higher cost of the use of incentive pay. The first effect outweighs the second effect. Similarly, a large $h$ implies that a given increase in effort leads only to a small increase in the probability of success. Hence, the agent responds weakly to incentives when $h$ is large. This effect outweighs the effect of lower cost of incentive pay through lower (infra-marginal) effort.

Proposition 5 implies that if incentive pay is imperfect, other organizational responses to reduce the commitment problem can be more effective than incentive pay or can be used jointly with incentive pay. This brings us back to Proposition 2, which shows that, if possible, the principal optimally uses a mixture of organizational missions, task-specific investments, and incentive pay. We now discuss the three main insights that Proposition 2 yields. Corollary 2a presents the first insight.

Corollary 2a Stronger internalization of the organizational mission (higher $\alpha$ ) leads to a stronger mission $p$, weaker incentive pay $F$, and higher investment $I$.

Organizational missions and incentive pay are substitutes. If a mission is more effective (higher $\alpha$ ), the strength of the organizational mission $p$ increases, whereas the optimal bonus $F$ decreases. For a given level of incentive pay, an increase in $\alpha$ leads to higher effort, both directly and through the accompanying increase in mission $p$. This makes it more likely that the principal has to pay out the bonus, leading to an increase in the cost of providing incentive pay. If the mission is fully internalized by the agent $(\alpha=1)$, the principal optimally abstains from using incentive pay, $F=0$. The reason is that if $\alpha=1$, an organizational mission can fully 
solve the commitment problem. Incentive pay, by contrast, is at most an imperfect solution for the commitment problem. Corollary $2 \mathrm{~b}$ describes the second main insight of Proposition 2.

Corollary 2b Lower cost of firm's task-specific investment (higher $\theta$ ) leads to higher investment $I$, a stronger mission $p$, and stronger incentive pay $F$.

The principal's investment in task $A$-specific productivity is complementary to both incentive pay and the strength of the organizational mission. The benefits of this investment depends on the probability that task $A$ is maintained, which depends positively on the agent's first-period effort. In other words, as the principal's investment and the agent's efforts are complements through their task-specific nature, other policies that increase the agent's effort become more rewarding as $I$ increases. This implies that firms that engage in exploration but also want to provide incentives for investment in current task-specific human capital are most successful when implementing a coherent set of policies concerning investment, missions, and incentives. These policies reduce the probability that the firm's explorative activities leads to actual changes. From an ex post perspective, the firm has too high barriers to change, yielding excess inertia. However, it is exactly this excess inertia that makes it worthwhile for employees to invest in specific skill formation.

Third, the three organizational responses to the commitment problem move together when the environment changes. In particular, if effort is more important or rewarding (higher $\lambda$ ) or if the environment is more stable (lower $h)$, the principal optimally chooses a stronger mission, invests more in task $A$-specific productivity, and sets stronger incentive pay. These comparative statics follows from expressions (14), (15), and (16), and are captured in Corollary 2c.

Corollary 2c Optimal investment $\hat{I}$, mission $\hat{p}$, and incentive pay $\hat{F}$ increase (decrease) in $\lambda(h)$.

The implication of these results is that even though incentive pay and organizational missions are substitutes in inducing workers to invest in taskspecific skills, across organizations or even across tasks within an organization, incentive pay may go hand in hand with organizational missions. Organizations in more volatile environments optimally maintain some flexibility by reducing task-specific investments and limiting the strength of the orga- 
nizational mission and incentive pay. Similarly, when an employee's effort responds strongly to incentives, organizations combine incentive pay with strong missions and high task-specific investments. ${ }^{20}$

Our model predicts that in ambidextrous firms, the return to exploration decreases in the strength of specific investments (both by the firm and by employees) and of incentive pay, and in the emphasis on organizational missions. Hence, from a positive perspective, our analysis provides predictions on how the relation between ambidexterity and firm performance is affected by other organizational policies, as called for by Raisch et al. (2009). From a normative perspective, a direct implication of Corollary $2 \mathrm{c}$ is that more emphasis on exploration should go hand in hand with less specific investments (both by the firm and by employees), weaker incentive pay, and less emphasis on organizational missions.

To conclude our analysis, we show that if the principal decides not to engage in exploration, the principal neither uses incentive pay nor organizational missions to induce additional effort. She does invest in task $A$-specific productivity, but only because this raises the expected probability of success in the second period. This investment does not affect the agent's first-period effort.

Proposition 6 If the principal does not engage in exploration, she optimally sets $F=0$ and $I=\theta$. The organizational mission $p$ is irrelevant. A larger $\alpha$ and the possibility to use incentive pay make exploration more attractive relative to not exploring, while the relative attractiveness of exploration decreases in $\theta$.

Proof. See Appendix.

Organizational missions do not affect effort when the principal does not engage in exploration, because in this situation the agent cannot affect the probability that task $A$ is maintained. Furthermore, incentive pay is too costly due to the large (infra-marginal) first-period effort that arises because the agent is certain that task $A$ is maintained in period 2. For the same

\footnotetext{
${ }^{20}$ Assuming a positive discount factor (instead of the no-discounting assumption we use throughout) makes policies that have first-period cost less attractive relative to policies that impose a cost in second period. Hence, the relative importance of missions increases in the discount factor compared to incentive pay and the firm's specific investment. Discounting does not affect the qualitative results in Corrolaries 2a, 2b, and 2c.
} 
reason, the principal optimally makes high task-specific investments. ${ }^{21}$ As in Section 3, the downside of abstaining from exploration is that profitable alternatives cannot be discovered.

It follows that compared to the base model in Section 3, exploration becomes more attractive when missions are effective (high $\alpha$ ) as well as well the principal can use incentive pay. Both policies reduce the time-inconsistency problem that leads to sub-optimally low effort, and thereby reduce the cost of exploration. The principal's task-specific investment, on the other hand, increases the expected probability of second-period success under exploration but increases the probability of success without exploration even further. Hence, part of the cost of not engaging in exploration can be recovered through higher investment, making exploration less attractive.

Proposition 6 yields the following prediction. Firms that do not engage in exploration are specialized, in the sense that employees have strong specific skills and are likely to work with specifically designed equipment or software. These employees receive little incentive pay, although their pay can be tied to the firm's performance. These firms have no visionary leaders, but aim to be experts in their fields, and respond slowly to changes in their environment. This corresponds to Ruef (1997), who documents that more specialized hospitals are less likely to respond to changes in the regulatory environment.

\section{Concluding Remarks}

This paper has developed a simple principal-agent model of investments in task-specific human capital and task assignment when employees are uncertain about future task assignment. We have shown that organizations can use a combination of organizational missions, incentive pay, and taskspecific investment to reduce the probability of a change in tasks beyond the ex post optimal level. Even though the optimal combination yields excess inertia from an ex post perspective, organizations expect to benefit from increased employee investment in task-specific skills. The most important predictions that follow from our analysis are the following. First, incentive pay and missions are substitutes. Second, firm's specific investments are

\footnotetext{
${ }^{21}$ If the principal can commit to maintain task $A$ whenever $\mu<z$, a similar result arises: the principal neither uses missions nor incentive pay and makes relatively high task-specific investments.
} 
complementary to both incentive pay and missions. Third, the strength of missions, incentive pay, and specific investments is lower in organizations that operate in environments were exploration is relatively important compared to organizations that operate in more stable environments. Fourth, the return to (more) exploration in ambidextrous firms decreases in the strength of missions, incentive pay, and specific investments (both by the firm and by the employees).

The impact of extending our two-period model to a multi-period model depends on the rate of decay of task-specific human capital. Under high rates of decay, organizations optimally maintain the lower probability of task change. If decay is slow and the learning curve is strictly concave in past efforts, the benefits of excess inertia reduce over time. Hence, firms may initially set policies that reduce the probability of task change, and later revert to policies that reduce inertia. This can give rise to punctuated equilibria (Burgelman 2002, Gupta et al. 2006), where organizations alternate between periods of exploration and periods of exploitation.

We have cast our analysis in a simple model with one agent who can invest in task-specific productivity. Our arguments extend directly to situations where project success depends on the degree of coordination among multiple agents, as in Bolton et al. (2013), Ferreira and Kittsteiner (2014), and Van den Steen (2012). If the development of project-specific routines requires coordinated efforts among agents, impediments to organizational change can boost agents' incentives to coordinate. Insofar as this leads to effective routines, this further decreases the probability of project change.

\section{References}

[1] Amburgey, Terry L., Dawn Kelly, and William P. Barnett, 1993, Resetting the Clock: The Dynamics of Organizational Change and Failure, Administrative Science Quarterly, vol. 38(1), pp. 51-73.

[2] Benner, M. J. and M. L. Tushman, 2003, Exploitation, Exploration, and Process Management: The Productivity Dilemma Revisited, Academy of Management Review, vol. 28, pp. 238-256.

[3] Besley, Timothy, and Maithreesh Ghatak, 2005, Competition and Incentives with Motivated Agents, American Economic Review, vol. 95(3), pp. 616-636. 
[4] Becker, Gary S., 1962, Investment in Human Capital: A Theoretical Analysis, Journal of Political Economy, vol. 70(5), pp. 9-49.

[5] Beckman, Christine M., 2006, The Influence of Founding Team Company Affiliations on Firm Behavior, Academy of Management Review, vol. 49(4), pp. 741-758.

[6] Bolton, Patrick, Markus K. Brunnermeier, and Laura Veldkamp, 2012, Leadership, Coordination, and Corporate Culture, Review of Economic Studies, vol. 80(2), pp. 512-537.

[7] Boyer, Marcel, and Jacques Robert, 2006, Organizational Inertia and Dynamic Incentives, Journal of Economic Behavior $\&$ Organization, vol. 59, 324-348.

[8] Burgelman, Robert A., 2002, Strategy as Vector and the Inertia of Coevolutionary Lock-in, Administrative Science Quarterly, vol. 47(2), pp. 325-357.

[9] Chari, V.V., and Hugo Hopenhayn, 1991, Vintage Human Capital, Growth, and the Diffusion of New Technology, Journal of Political Economy, vol. 99(6), pp. 1142-1165.

[10] David, Paul A., 1985, Clio and the Economics of QWERTY, American Economic Review, vol. 75, pp. 332-337.

[11] Dessein, Wouter, and Tano Santos, 2006, Adaptive Organizations, Journal of Political Economy, vol. 114(5), pp. 956-995.

[12] Downs, Anthony, 1967, Inside Bureaucracy, Boston: Little, Brown.

[13] Ferreira, Daniel, and Thomas Kittsteiner, 2014, When Does Competition Foster Commitment?, mimeo, London School of Economics.

[14] Ferreira, Daniel, and Marcelo Rezende, 2007, Corporate Strategy and Information Disclosure, RAND Journal of Economics, vol. 38(1) pp. 164-184.

[15] Ford, Jeffrey D., Laurie W. Ford, and Angelo D'Amelio, 2008, Resistance to Change: The Rest of the Story, Academy of Management Review, vol. 33(2), pp. 362-377.

[16] Francois, Patrick, 2007, Making a Difference, RAND Journal of Economics, vol. 38(3), pp. 714-732. 
[17] Gathmann, Christina, and Uta Schönberg, 2010, How General is Human Capital? A Task-Based Approach, Journal of Labor Economics, vol. 28(1), pp. 1-49.

[18] Garud, Raghu, Arun Kumaraswamy, and Peter Karnoe, 2010, Path Dependence or Path Creation, Journal of Management Studies, vol. 47(4), pp. 760-774.

[19] Ghosh, Suman, and Michael Waldman, 2010, Standard Promotion Practices Versus Up-or-Out Contracts, RAND Journal of Economics, vol. 41(2) pp. 301-325.

[20] Gibbons, Robert, and Michael Waldman, 2006, Enriching a Theory of Wage and Promotion Dynamics inside Firms, Journal of Labor Economics, vol. 24(1), pp. 59-107.

[21] Greve, Henrich R., 2007, Exploration and Exploitation in Product Innovation, Industrial and Corporate Change, vol. 16(5), pp. 945-975.

[22] Gupta, Anil K., Ken G. Smith, and Christina E. Shalley, 2006, The Interplay between Exploration and Exploitation, Academy of Management Journal, vol. 49(4), pp. 693-706.

[23] Griliches, Zvi, 1975, Hybrid Corn: An Exploration in the Economics of Technological Change, Econometrica, vol. 25(4), pp. 501-522.

[24] Hart, Oliver, and John Moore, 1990, Property Rights and the Nature of the Firm, Journal of Political Economy, vol. 98(6), pp. 1119-1158.

[25] Hannan, Michael T., and John Freeman, 1984, Structural Inertia and Organizational Change, American Sociological Review, vol. 49(2), pp. 149-164.

[26] Inderst, Roman, and Holger M. Mueller, 2007, Safeguarding Specific Human Capital Investments, mimeo, New York University.

[27] Jovanovic, Boyan, and Glenn MacDonald, 1994, Competitive Diffusion, Journal of Political Economy, vol. 102(1), pp. 24-52.

[28] Jovanovic, Boyan, and Yaw Nyarko, 1995, A Bayesian Learning Model Fitted to a Variety of Empirical Learning Curves, Brookings Papers on Economic Activity: Microeconomics, vol. 1995, pp. 247-305.

[29] Kahn, Charles, and Gur Huberman, 1988, Two-Sided Uncertainty and "Up-or-Out" Contracts, Journal of Labor Economics, vol. 6(4), pp. 423444. 
[30] Katz, Michael L., and Carl Shapiro, 1986, Technology Adoption in the Presence of Network Externalities, Journal of Political Economy, vol. 94(4), pp. 822-841.

[31] Kelly, Dawn., and Terry L. Amburgey, 1991, Organizational Inertia and Momentum: A Dynamic Model of Strategic Change, Academy of Management Journal, vol. 34(3), pp. 591-612.

[32] Lance, Charles E., Jerry W. Hedge, and Williams E. Alley, 1989, Joint Relationships of Task Proficiency with Aptitude, Experience, and Task Difficulty: A Cross-level, Interactional Study, Human Performance, vol. 2(4),pp. 249-272.

[33] Lavie, Dovev , Uriel Stettner, and Michael L. Tushman, 2010, Exploration and Exploitation Within and Across Organizations, Academy of Management Annals, vol. 4(1), pp. 109-155.

[34] Lazear, Edward P., 2009, Firm-Specific Human Capital: A SkillWeights Approach, Journal of Political Economy, vol. 117(5), pp. 914940.

[35] Leonard-Barton, Dorothy, 1992, Core Capabilities and Core Rigidities: A Paradox in Managing New Product Development, Strategic Management Journal, vol. 13(S1), pp. 111-125.

[36] Levitt, Barbara, and James G. March, 1988, Organizational Learning, Annual Review of Sociology, vol. 14, pp. 319-340.

[37] Mailath, George J., Volker Nocke, and Andrew Postlewaite, 2004, Business Strategy, Human Capital, and Managerial Incentives, Journal of Economics $\& 3$ Management Strategy, vol. 13(4), pp. 617-633.

[38] March, James G., 1981, Footnotes to Organizational Change, Administrative Science Quarterly, vol. 26(4), pp. 563-577.

[39] March, James G., 1991, Exploration and Exploitation in Organizational Learning, Organization Science, vol. 2(1), pp. 71-87.

[40] Miller, Danny, and Ming-Jer Chen, 1994, Sources and Consequences of Competitive Inertia: A Study of the US Airline Industry, Administrative Science Quarterly, vol. 39(1), pp. 1-23.

[41] Nelson, Richard R., and Sydney G. Winter, 1982, An Evolutionary Theory of Economic Change. Cambridge: Harvard University Press. 
[42] Prendergast, Canice, 1993, The Role of Promotion in Inducing Specific Human Capital Acquisition, Quarterly Journal of Economics, vol. 108(2), pp. 523-534.

[43] Quinones Miguel A., J. Kevin Ford, and Mark S. Teachout, 1995, The Relationship Between Work Experience and Job Performance: A Conceptual and Meta-Analytic Review, Personnel Psychology vol. 48(4), pp. 887-910.

[44] Raisch, Sebastian, Julian Birkinshaw, Gilbert Probst, and Michael L. Tushman, 2009, Organizational Ambidexterity: Balancing Exploitation and Exploration for Sustained Performance, Organization Science, vol. 20(4), pp. 685-695.

[45] Rotemberg, Julio J., and Garth Saloner, 1993, Leadership Style and Incentives, Management Science, vol. 39(11), pp. 1299-1318.

[46] Rotemberg, Julio J., and Garth Saloner, 1994, Benefits of Narrow Business Strategies, American Economic Review, vol. 85(5), pp. 1330-1349.

[47] Rotemberg, Julio J., and Garth Saloner, 2000, Visionaries, Managers, and Strategic Direction, RAND Journal of Economics, vol. 31(4), pp. 693-716.

[48] Ruef, Martin, 1997, Assessing Organizational Fitness on a Dynamic Landscape: An Empirical Test of the Relative Inertia Thesis, Strategic Management Journal, vol. 18(11), pp. 837-853.

[49] Rumelt, R.P., 1995, Inertia and transformation. In: C.A. Montgomery (Ed.), Resource-based and evolutionary theories of the firm, Dordrecht: Kluwer Academic Publishers.

[50] Schaefer, Scott, 1998, Influence Cost, Structural Inertia, and Organizational Change, Journal of Economics $\& 3$ Management Strategy, vol. $7(2)$, pp. 237-263.

[51] Schmidt, Frank L., John E. Hunter, and Alice N. Outerbridge, 1986, Impact of Job Experience and Ability on Job Knowledge, Work Sample Performance, and Supervisory Ratings of Job Performance, Journal of Applied Psychology, vol. 71(3), pp. 432-439.

[52] Schreyögg, Georg, and Jörg Sydow, 2011, Organizational Path Dependence: A Process View, Organization Studies, vol. 32(3), pp. 321-335. 
[53] Stoneman, P., 1983, The Economic Analysis of Technological Change, Oxford: University Press.

[54] Sydow, Jörg, Georg Schreyögg, and Jochen Koch, 2009, Organizational Path Dependence, Opening the Black Box, Academy of Management Review, vol. 34(4), pp. 689-709.

[55] Uotila, Juha, Markku Maula, Thomas Keil, Shaker A. Zahra, Exploration, Exploitation, and Financial Performance: Analysis of S\&P 500 Corporations, Strategic Management Journal, vol. 30, pp. 221-231.

[56] Van den Steen, Eric, 2005, Organizational Beliefs and Managerial Vision, Journal of Law, Economics, \& Organization, vol. 21(1), pp. 256283.

[57] Van den Steen, Eric, 2012, A Theory of Explicitly Formulated Strategy, Harvard Business School Working Paper, No. 12-102.

[58] Vergne, Jean-Philippe, and Rodolphe Durand, 2011, The Path of Most Persistence, An Evolutionary Perspective on Path Dependence and Dynamic Capabilities, Organization Studies, vol. 32(3), pp. 365-382.

[59] Voss, Glenn B. and Zannie G. Voss, 2013, Strategic Ambidexterity in Small and Medium-Sized Enterprises: Implementing Exploration and Exploitation in Product and Market Domains, Organization Science, vol. 24(5), pp. 1459-1477.

[60] Waldman, J. Deane, Steven A. Yourstone, and Howard L. Smith, 2003, Learning Curves in Health Care, Health Care Management Review vol. 28(1), pp. 41-54.

[61] Wang, Heli, and Kin Fai Ellick Wong, 2012, The Effect of Managerial Bias on Employees' Specific Human Capital Investments, Journal of Management Studies, vol. 49(8), pp. 1435-1458.

[62] Wilson, James Q., 1989, Bureaucracy: What Government Agencies Do and Why They Do It, New York: Basic Books.

\section{A Appendix}

\section{A more general productivity distribution of alternative tasks}

In the main text, we have assumed that the productivity of task $B$ is uniformly distributed. Here, we show the effect of assuming a more general 
distribution of the alternative task's productivity on the effect of a biased principal. For brevity, we focus on the case where the principal can neither offer incentive pay nor make task-specific investments, $F=I=0$.

Suppose $\mu$ is distributed according to twice continuously differentiable density $g(\cdot)$ over support $[-h, h]$ with cumulative density function $G(\cdot)$, so that $G(-h)=0$ and $G(h)=1$. The expected value of $\mu$ equals zero, $\int \mu g(\mu) d \mu=0$. The principal has predisposition $p$, such that the principal keeps task $A$ if and only if $\mu<e_{1}+p$. This happens with probability $G\left(e_{1}+p\right)$. The expected value of $\mu$ given that $\mu>e_{1}+p$ is given by $\bar{\mu}(p)=\int_{e_{1}+p}^{h} \mu \frac{g(\mu)}{\left(1-G\left(e_{1}+p\right)\right)} d \mu$. Assume for ease of exposition that the agent does not share the principal's vision, $\alpha=0$. The agent's optimal first-period effort is given by maximizing

$$
\begin{aligned}
E\left[U_{1}+U_{2}-c\left(e_{1}\right)-c\left(e_{2}\right)\right]= & e_{1}-\frac{1}{2 \lambda}\left(e_{1}\right)^{2}+G\left(e_{1}+p\right)\left(e_{1}+\lambda\right)+ \\
& +\left(1-G\left(e_{1}+p\right)\right)(\lambda+\bar{\mu}(p))-\frac{1}{2} \lambda
\end{aligned}
$$

which gives first-order condition (using Leibniz' rule)

$$
1-\frac{e_{1}}{\lambda}+G\left(e_{1}+p\right)-p g\left(e_{1}+p\right)=0
$$

A higher $p$ has a positive effect on incentives through an increase in the probability of maintaining task $A, G\left(e_{1}+p\right)$, but the last term on the lefthand side shows that it also has a negative effect through a decrease in the benefit of the marginally maintained task (i.e. when $\mu=e_{1}+p$, which happens with probability $g\left(e_{1}+p\right)$, yielding a payoff that is $p$ lower than the agent's payoff from switching to task $B$ ). Totally differentiating gives

$$
\frac{d e_{1}}{d p}=\frac{\lambda p g^{\prime}\left(e_{1}+p\right)}{\lambda g\left(e_{1}+p\right)-\lambda p g^{\prime}\left(e_{1}+p\right)-1} .
$$

As the numerator is the second-order condition for optimal effort, which must be negative, the sign of this expression depends on whether $g(\cdot)$ is increasing or decreasing at $\mu=e_{1}+p$. With a uniform distribution, $g^{\prime}(\cdot)=0$, so that effort is constant in $p$. If $g(\cdot)$ is bell-shaped and symmetric around zero, we have that $g(\cdot)$ is strictly decreasing in $\mu$ for $0<\mu<h$, and effort increases in $p$. 
The intuition is as follows. An increase in $p$ has three effects. First, a higher probability of continuing task $A$. Second, the average productivity of task $B$ given a change in tasks is higher, as the payoff of the marginal task increases in $p$. These two effects cancel out. Third, a change in the probability that the agent's marginal effort results in continuation (which the agent prefers to avoid as task $B$ is better from his perspective given that realization of $\mu$ ). When density function $g(\cdot)$ is decreasing over $[0, h]$, the probability that the agent's marginal effort is pivotal decreases in $p$.

\section{Proof of Proposition 6}

Without exploration, the optimal first-period effort for the agent is $e_{1}=$ $\lambda(2+F)$. The principal maximizes

$$
U_{1}+U_{2}=e_{1}(1-F)-\frac{1}{2 \theta} I^{2}+e_{1}+I+\lambda
$$

with respect to $p, F$, and $I$. This shows that $p$ is irrelevant. First-order conditions for $I$ and $F$ are, respectively, $\frac{-I}{\theta}+1=0$ and $-\lambda(2+F)+2 \lambda=0$, implying that $I=\theta$ and $F=0$. Substituting this into the principal's payoff function yields

$$
U_{1}+U_{2}=5 \lambda+\frac{1}{2} \theta
$$

With exploration, the principal's payoff is given by using (14), (15), and (16) to substitute for $\hat{p}, \hat{I}$, and $\hat{F}$, respectively, in the principal's expected payoff (17) with $\pi^{M}$ given by (12) and $e_{1}^{*}(p, \alpha, I, F)$ by (13). This gives

$$
E\left[U_{1}+U_{2}\right]=\frac{4 h\left(h^{2}+12 h \lambda-4 \theta \lambda-\left(3+\alpha^{2}\right) \lambda^{2}\right)+\left(h^{2}-2 \theta \lambda\right)\left(1-\alpha^{2}\right) \lambda}{4 h\left(4 h-\left(3+\alpha^{2}\right) \lambda\right)-2 \theta\left(4 h+\left(1-\alpha^{2}\right) \lambda\right)} .
$$

Hence, the principal optimally engages in exploration whenever the cost of exploration are smaller than

$$
\hat{c}=\frac{4 h\left(h^{2}+12 h \lambda-4 \theta \lambda-\left(3+\alpha^{2}\right) \lambda^{2}\right)+\left(h^{2}-2 \theta \lambda\right)\left(1-\alpha^{2}\right) \lambda}{4 h\left(4 h-\left(3+\alpha^{2}\right) \lambda\right)-2 \theta\left(4 h+\left(1-\alpha^{2}\right) \lambda\right)}-5 \lambda+\frac{1}{2} \theta .
$$

Comparative statics show that $\hat{c}$ increases in $\alpha$ and decreases in $\theta$ :

$$
\begin{aligned}
\frac{\partial \hat{c}}{\partial \alpha} & =\frac{8 h \alpha \lambda^{2}(3 h-\theta)^{2}}{\left(2 h\left(4 h-\left(3+\alpha^{2}\right) \lambda\right)-\theta\left(4 h+\left(1-\alpha^{2}\right) \lambda\right)\right)^{2}}>0 . \\
\frac{\partial \hat{c}}{\partial \theta} & =-\frac{(3 h-\theta)\left(4 h+\left(1-\alpha^{2}\right) \lambda\right)\left(\left(4 h+\left(1-\alpha^{2}\right) \lambda\right)(h-4 \lambda-\theta)+4\left(1-\alpha^{2}\right) \lambda^{2}\right)}{2\left(2 h\left(4 h-\left(3+\alpha^{2}\right) \lambda\right)-\theta\left(4 h+\left(1-\alpha^{2}\right) \lambda\right)\right)^{2}}<0 .
\end{aligned}
$$


Lastly, that the possibility to use incentive pay makes exploration relatively more attractive follows directly from the fact that the principal's payoff without exploration does not depend on bonus $F$ while the principal optimally sets a positive bonus in case of exploration. 